\title{
IGF1 deficiency in newly diagnosed Graves' disease patients
}

\author{
Sorina Martin, ${ }^{1,2}$ Anca Sirbu, ${ }^{1,2,3}$ Minodora Betivoiu, ${ }^{2}$ Suzana Florea, ${ }^{4}$ \\ Carmen Barbu, ${ }^{1,2}$ Simona Fica ${ }^{1,2}$
}

${ }^{1}$ Endocrinology Department, Carol Davila University of Medicine and Pharmacy; ${ }^{2}$ Endocrinology Department, Elias Hospital; ${ }^{3}$ Victor Babes Institute; ${ }^{4}$ Laboratory Department, Elias Hospital; Bucharest, Romania

\begin{abstract}
OBJECTIVE: Thyroid hormones influence the GH/IGF1 axis, but previous studies have reported discrepant results regarding serum IGF1 levels in hyperthyroidism. We have therefore investigated, at diagnosis, the relationship between serum IGF1 levels and the main characteristics of Graves' disease (GD): severity of hyperthyroidism, goiter size, presence of active Graves' ophthalmopathy (GO), antythyroid antibodies status and titer. DESIGN AND METHODS: This cross-sectional study included 98 newly diagnosed hyperthyroid patients with GD who presented consecutively at our clinic. The main measured parameters were: TSH, FT4, FT3, TT3, thyroglobulin, anti-thyroid peroxidase antibodies (TPOAb), anti-thyroglobulin antibodies (ATA), thyrotropin receptor antibodies (TRAb), IGF1. Patients were considered IGF deficient if IGF1 $\mathrm{z}$ score was $\leq-2$ SD from mean for age. RESULTS: In GD patients, men had higher IGF1 levels $(p=0.023)$ and IGF1 $z$ scores $(p=0.013)$ than women. $18.4 \%$ of GD patients were, at diagnosis, IGF1 deficient. Compared to patients without IGF 1 deficiency, these patients presented higher thyroglobulin (median=72.55, IQR=116.02 vs median=11.40, IQR=80.74 ng/ml, $\mathrm{p}=0.002$ ) and FT3 (median=11.30, IQR=7.64 vs median=7.33, IQR=5.72 pg/ml, p=0.027), and lower ATA (median=20, IQR=0 vs median=34.05, IQR=161 iu/ml, $p<0.001$ ) levels. Thyroglobulin was independently associated with IGF1 deficiency (AUROC $=0.732,95 \%$ CI: 0.620-0.844, p $=0.002$; cut-off for thyroglobulin=50.40 $\mathrm{ng} / \mathrm{ml}, \mathrm{Se}=\mathbf{7 7 . 8 \%}, \mathrm{Sp}=\mathbf{7 0} \%$ ). IGF1 status was not influenced by gender $(p=0.084)$, current smoking $(p=0.558)$, goiter size $(p=0.533)$, active ophthalmopathy $(p=0.334)$, TRAb $(p=0.239)$ or TPOAb status $(p=0.367)$. CONCLUSIONS: Nearly one fifth of newly diagnosed GD patients had IGF1 deficiency. IGF1 deficiency was associated with lower ATA titers, higher thyroglobulin levels and more severe FT3 hyperthyroidism at diagnosis.
\end{abstract}

Key words: Anti-thyroglobulin antibodies, IGF1, IGF1 deficiency, Graves' disease, Thyroglobulin

Address for correspondence:

Simona Fica, Prof., MD, PhD, FACE, Endocrinology

Department, Carol Davila University of Medicine and Pharmacy

Elias Hospital, Marasti Avenue 17, 011461 Bucharest, Romania;

Tel./Fax: +40 213161614,

E-mail address: simonafica@yahoo.com

Received 11-02-2015, Accepted 14-05-2015

\section{INTRODUCTION}

Graves' disease (GD) is an autoimmune disorder characterized by diffuse goiter and thyrotoxicosis which can be accompanied by ophthalmopathy and, rarely, dermopathy.

While the role of thyrotropin receptor antibodies 
(TRAb) and thyrotropin receptor (TSHR) in GD hyperthyroidism is well established ${ }^{1}$ and a correlation appears to exist between TRAb levels and the clinical activity of Graves' ophthalmopathy (GO), ${ }^{2}$ whether TRAb or TSHR plays a role in extrathyroidal manifestations of GD has not been resolved., ${ }^{3,4}$ The role of the IGF1/IGF1R pathway in the pathogenesis of GD was recently studied, although the relationship between the thyroid and IGF1 was first described in the 80 s. ${ }^{5}$ IGF1 and IGF1R may be actively involved early in the pathogenesis of GD. It appears that both TSHR and IGF1R contribute to GD pathogenesis and together may comprise a physical and functional complex in thyroid and orbital tissue of GD patients. ${ }^{6,7}$

Thyroid hormones influence the GH/IGF1 axis, having a permissive role in GH/IGF1 action and a specific effect on plasma levels of some of the GHindependent IGF binding proteins (IGFBPs). Previous studies have reported discrepant results regarding serum levels of IGF1 in hyperthyroidism. In 1995, J. Frystyk et al showed that, in rats, hyperthyroidism increases the circulating low-molecular IGFBPs and induces a reduction in free IGF1, which may play a central role in regulation of IGF bioactivity by thyroid hormones. ${ }^{8}$ Another study from the same year reported reduced IGF1 circulating levels in hyperthyroid patients, possibly due to nutritional factors. ${ }^{9}$ Iglesias et al demonstrated in 2001 that hypothyroidism is associated with significant reductions of IGF1 and IGFBP 3 and that IGFBP1 is elevated in both hypothyroidism and hyperthyroidism. ${ }^{10} \mathrm{Co} \mathrm{Ng}$ et al showed, in a study performed on adolescent hyperthyroid patients, that hyperthyroidism does not cause alterations in the serum concentrations of either free or total IGF1. In the same study, both serum IGFBP2 and IGFBP3 concentrations were elevated during hyperthyroidism and correlated with serum T4 levels. These abnormalities reversed with normalization of thyroid function. ${ }^{11}$ Other studies revealed that hyperthyroidism is associated with increased serum IGF1 levels, decreased $\mathrm{GH}$ responsiveness to GHRH at the pituitary level and a lack of suppressive effect of an oral glucose load at the hypothalamic level. ${ }^{12}$ IGF1 was positively correlated with free T3 (FT3) and free T4 (FT4) and negatively correlated with TSH. ${ }^{13}$ Lakatos et al reported that IGF1 levels were significantly increased in hyperthyroid patients before treatment, correlated with serum FT4 levels and returned to normal after treatment with methimazole. ${ }^{14}$ On the other hand, serum IGF and IGFBP levels were not reported to be elevated in GD patients with active GO. ${ }^{15}$

The aim of this study was to investigate the relationship between serum IGF1 levels and the main characteristics of GD (severity of hyperthyroidism, goiter size, presence of active GO, antythyroid antibodies status and titer) in a group of patients with newly diagnosed Graves' hyperthyroidism.

\section{SUBJECTS AND METHODS}

\section{Patients and study protocol}

This cross-sectional study included 98 patients with newly diagnosed GD hyperthyroidism, selected out of 239 patients consecutively evaluated for thyrotoxicosis in our clinic between 2008-2012. Exclusion criteria were: other etiologic forms of thyrotoxicosis, serious concomitant illnesses, pregnancy, diabetes mellitus, treatment with drugs known to influence the pituitary-thyroidal axis, pituitary disorders.

GD was defined as the presence of biochemical hyperthyroidism (raised serum FT4 and/or FT3 and/ or total T3 (TT3) concentration and suppresed TSH) together with two of the following: 1) diffuse goiter on sonographic scan, 2) significant titer of anti-thyroid peroxidase (TPOAb) and/or anti-thyroglobulin antibodies (ATA) and/or TRAb and 3) the presence of GO. At diagnosis, goiter size was categorized by a single observer on the basis of physical examination according to WHO criteria (http://www.who.int/iris/ handle/10665/61278. 12.01.2015). Eye disease was classified according to the presence of eye signs in categories 2-6 of the NOSPECS classification ${ }^{16}$ and the clinical activity score of GO was calculated. ${ }^{17}$

Serum TSH, FT4, FT3, TT3, thyroglobulin, TPOAb and ATA were assayed at a single laboratory using a two-site, solid-phase, enzyme-labeled chemiluminescent immunometric assay (Immulite 2000, Siemens Healthcare Diagnostics Products Ltd.). Reference ranges: $\mathrm{TSH}=0.4-4.0 \mathrm{miu} / \mathrm{L}, \mathrm{FT} 4=0.7-1.85 \mathrm{ng} / \mathrm{dL}$, FT3 $=1.8-4.2 \mathrm{pg} / \mathrm{mL}$, TT3=84-172 ng/dL, thyroglobulin $<55 \mathrm{ng} / \mathrm{ml}$, TPOAb $=10-35 \mathrm{iu} / \mathrm{mL}$ and ATA $<40$ $\mathrm{iu} / \mathrm{mL}$. Serum TRAb levels were measured using a second generation enzyme immunoassay, ELISA 
kit (DRG Instruments GmbH, Germany). Reference range: $<1 \mathrm{iu} / \mathrm{L}$ negative, $>1.5 \mathrm{iu} / \mathrm{L}$ positive. Antithyroid antibody status was defined as follows: ATA positive $=$ patients with ATA serum levels $>40 \mathrm{iu} / \mathrm{ml}$; TPOAb positive $=$ patients with TPOAb serum levels $>35$ $\mathrm{iu} / \mathrm{ml}$; TRAb positive $=$ patients with $\mathrm{TRAb}$ serum levels $>1.5 \mathrm{iu} / \mathrm{L}$. Serum tumor necrosis factor alpha (TNF alfa) was measured using an ELISA kit (DRG Instruments $\mathrm{GmbH}$, Germany); reference range: 4.6$12.4 \mathrm{pg} / \mathrm{ml}$. Serum high-sensitivity C-reactive protein (HS-CRP) was assayed using a two-site, solid-phase, enzyme-labeled chemiluminescent immunometric assay (Immulite 2000, Siemens Healthcare Diagnostics Products Ltd.); reference range: $<11 \mathrm{mg} / \mathrm{L}$. Serum IGF-1 was assayed using a two-site, solid-phase, enzyme-labeled chemiluminescent immunometric assay (Immulite 2000, Siemens Healthcare Diagnostics Products Ltd.). The analytical sensitivity was $20 \mu \mathrm{g} / \mathrm{l}$, the intra-assay CV was 2.3-3.9\% and the inter-assay CV was $3.7-8.1 \%$. Since IGF1 levels are age-dependent, we calculated the standard deviation score of IGF1 levels according to age (z score). Age-adjusted IGF1 values were referenced from a previously published study by Elmlinger et $\mathrm{al}^{18}$ that used the same assay as in our study. Patients were considered IGF1 deficient if IGF1 $\mathrm{z}$ score was $\leq-2 \mathrm{SD}$ from the mean for age. ${ }^{19}$

The study protocol was approved by the ethics committee of Elias Hospital. The study was conducted according to the standards of good clinical practice and the Declaration of Helsinki and all study patients signed an informed consent.

\section{Data presentation and statistical analyses}

Descriptive data are presented as means $\pm \mathrm{SD}$, medians with interquartile range (IQR) or percents. IGF1 and IGF1 z score were normally distributed. Because thyroglobulin and ATA were not normally distributed, their levels were transformed to their logarithms before regression analysis and graphical representation. Between-groups comparisons were carried out using parametric (independent sample t-test, one-way ANOVA) or nonparametric (MannWhitney U-test, Kruskal-Wallis one-way ANOVA) tests, as appropriate. $\chi^{2}$ test and Fisher's exact test were used to compare proportions in large and small groups, respectively. Relations between continuous variables were analyzed using Pearson's correla- tion parametric coefficient or Spearman's Rho nonparametric correlation coefficient. Linear regression analyses were performed to determine the influence of different predictors on serum IGF1 levels and on IGF1 z scores. Logistic regression analysis was used to identify the influence of different parameters on the presence of IGF1 deficiency. Results are presented as Odds Ratio (OR) for the predictor variable, 95\% confidence interval (CI) and $\mathrm{p}$ value for each variable assumed as a predictor. The overall validity of the model was measured using area under the receiver operating characteristic curve (AUROC) with 95\% CI. The SPSS statistical package for Windows, version 20.0. (SPSS Inc., Chicago IL, USA), was used to perform all statistical analysis. A $p$ value $<0.05$ indicated statistical significance.

\section{RESULTS}

A total number of 98 GD patients were evaluated: median age $42(\mathrm{IQR}=23)$ years, $78(79.6 \%)$ women, $33(33.7 \%)$ current smokers, 65 (66.3\%) with medium/ large goiters (grade $2 \mathrm{WHO}$ goiter grading system) and $24(24.5 \%)$ with active GO. Mean IGF1 at diagnosis was $169.90 \pm 82.46 \mathrm{ng} / \mathrm{ml}$ and IGF1 z score $-0.33 \pm 1.63$. After the initial laboratory evaluation, all patients received treatment with methimazole at a mean dose of $30.15 \pm 7.54 \mathrm{mg} /$ day. The demographic, clinical and laboratory characteristics of the 98 patients are summarized in Table 1.

At diagnosis, men had significantly higher mean serum IGF1 levels $(207.13 \pm 92.45$ vs $160.35 \pm 77.49$ $\mathrm{ng} / \mathrm{ml}, \mathrm{p}=0.023)$ and IGF1 $\mathrm{z}$ scores $(-0.46 \pm 1.68 \mathrm{vs}$ $-0.54 \pm 1.56 \mathrm{ng} / \mathrm{ml}, \mathrm{p}=0.013)$ compared to women. Current smokers and nonsmokers had similar serum IGF1 levels $(\mathrm{p}=0.901)$ and IGF1 $\mathrm{z}$ scores $(\mathrm{p}=0.663)$. There was no significant association between goiter size at diagnosis and serum IGF1 levels $(\mathrm{p}=0.895)$ or IGF $1 \mathrm{z}$ scores $(\mathrm{p}=0.766)$. There was no significant difference regarding serum IGF 1 levels $(p=0.136)$ or IGF1 z scores $(p=0.070)$ between GD hyperthyroid patients with active $\mathrm{GO}$ compared to patients without GO.

No correlations were found between serum inflamatory markers HS-CRP, TNF alfa and IGF1 levels $(\mathrm{p}=0.131$, respectively $\mathrm{p}=0.551)$ or IGF $1 \mathrm{z}$ scores $(\mathrm{p}=0.432$, respectively $\mathrm{p}=0.629)$. 
Table 1. Demographic, clinical and laboratory characteristics of the 98 newly diagnosed GD patients, according to the presence of IGF1 deficiency

\begin{tabular}{|c|c|c|c|c|}
\hline Parameter & $\begin{array}{c}\text { All } \\
(\mathrm{N}=98)\end{array}$ & $\begin{array}{l}\text { No IGF1 deficiency } \\
\qquad(\mathrm{N}=\mathbf{8 0})\end{array}$ & $\begin{array}{l}\text { IGF1 deficiency } \\
\qquad(\mathrm{N}=18)\end{array}$ & p \\
\hline Age at diagnosis median (IQR), (years) & $42(23)$ & $42(21)$ & $46(35)$ & 0.680 \\
\hline Current smoker N (\%) & $33(33.7)$ & $28(35)$ & $5(27.8)$ & 0.558 \\
\hline $\mathrm{BMI}$ mean $\pm \mathrm{SD},\left(\mathrm{kg} / \mathrm{m}^{2}\right)$ & $25.25 \pm 6.48$ & $24.49 \pm 5.53$ & $28.55 \pm 9.07$ & 0.023 \\
\hline \multicolumn{5}{|l|}{ Gender N (\%) } \\
\hline Females & $78(79.6)$ & $61(76.2)$ & $17(94.4)$ & 0.084 \\
\hline Goiter size N (\%) & & & & 0.533 \\
\hline Grade 0 & $3(3.1)$ & $3(3.8)$ & $0(0)$ & \\
\hline Grade 1 & $30(30.6)$ & $23(28.7)$ & $7(38.9)$ & \\
\hline Grade 2 & $65(66.3)$ & $54(67.5)$ & $11(61.1)$ & \\
\hline Ophthalmopathy N (\%) & $24(24.5)$ & $18(22.5)$ & $6(33.3)$ & 0.334 \\
\hline TSH median (IQR), (miu/L) & $0.006(0.010)$ & $0.006(0.011)$ & $0.005(0.005)$ & 0.510 \\
\hline FT4 median (IQR), (ng/dl) & $3.57(3.35)$ & $3.35(3.20)$ & $4.66(3.18)$ & 0.235 \\
\hline TT3 median (IQR), (ng/ml) & $331.16(293.60)$ & $318.50(283.00)$ & $417.00(302.00)$ & 0.168 \\
\hline FT3 median (IQR), (pg/ml) & $8.26(6.30)$ & $7.33(5.72)$ & $11.30(7.64)$ & 0.027 \\
\hline Thyroglobulin median (IQR), (ng/ml) & $25.45(88.55)$ & $11.40(80.74)$ & $72.55(116.02)$ & 0.002 \\
\hline TPOAb median (IQR), (iu/ml) & $77.15(637.62)$ & $234.70(940.25)$ & $57.45(578.60)$ & 0.270 \\
\hline ATA median (IQR), (iu/ml) & $20.00(51.00)$ & $34.05(161.00)$ & $20.00(0)$ & $<0.001$ \\
\hline TRAb median (IQR), (iu/L) & $6.12(14.45)$ & $8.50(15.40)$ & $8.51(32.86)$ & 0.690 \\
\hline HS-CRP median (IQR), (mg/L) & $2.00(5.10)$ & $1.91(5.07)$ & $2.65(4.51)$ & 0.388 \\
\hline TNF $\alpha$ median (IQR), (pg/ml) & $7.50(5.12)$ & $7.55(5.07)$ & $7.50(5.05)$ & 0.752 \\
\hline
\end{tabular}

Data are presented as percents, mean \pm SD or median (IQR) according to the type of the variable and the normality of distribution. P value for comparison between GD patients with and without IGF1 deficiency. IGF1 deficiency: IGF1 z score $\leq-2$ DS.

GD: Graves' disease; N: number of cases; IGF1: Insulin-like growth factor 1; IQR: interquartile range; SD: standard deviation; BMI: body mass index; TSH: thyroid-stimulating hormone; FT4: free thyroxine; FT3: free triiodothyronine; TT3: total triiodothyronine; TPOAb: anti-thyroperoxidase antibodies; ATA: anti-thyroglobulin antibodies; TRAb: thyroid-stimulating hormone receptor antibodies; HS-CRP: high-sensitivity C-reactive protein; TNF alpha: tumor necrosis factor alpha.

Eighty-nine (89) (90.81\%) patients were TRAb positive, $66(67.30 \%)$ were TPOAb positive and 38 $(38.80 \%)$ were ATA positive. TRAb and TPOAb positive patients had similar serum IGF1 levels ( $\mathrm{p}=0.440$, respectively $\mathrm{p}=0.640)$ and IGF $1 \mathrm{z}$ scores $(\mathrm{p}=0.489$, respectively $\mathrm{p}=0.785$ ) when compared to TRAb and TPOAb negative patients, respectively. ATA positive patients had significantly higher serum IGF1 levels $(191.82 \pm 72.49$ vs $156.01 \pm 85.89 \mathrm{ng} / \mathrm{ml}, \mathrm{p}=0.036)$ and IGF1 z scores $(0.12 \pm 1.33$ vs $-0.63 \pm 1.74 \mathrm{ng} / \mathrm{ml}$, $\mathrm{p}=0.024$ ) compared to ATA negative patients.

Serum IGF1 was positively correlated with ATA levels $(\mathrm{r}=0.306, \mathrm{p}=0.002)$ and negatively correlated with $\log$ serum thyroglobulin $(r=-0.394, p<0.001)$ (Figure 1A). IGF1 z scores were positively correlated with ATA levels ( $\mathrm{r}=0.306, \mathrm{p}=0.002)$ and negatively correlated with log serum thyroglobulin $(\mathrm{r}=-0.426$, $\mathrm{p}<0.001)$ (Figure 1B) and FT3 $(\mathrm{r}=-0.314, \mathrm{p}=0.008)$ (Figure 2).

Simple linear regression analysis showed that in GD patients, higher FT3 ( $\mathrm{p}=0.044)$ and thyroglobulin $(p<0.001)$, and respectively lower ATA $(p=0.027)$ levels are associated, at diagnosis, with lower IGF1 z scores (Table 2).

IGF1 deficiency (IGF1 z score $\leq-2$ DS) was present in $18(18.4 \%)$ patients. Compared to patients without IGF1 deficiency (mean IGF1 $192.88 \pm 72.50 \mathrm{ng} / \mathrm{ml}$, IGF1 z score $0.17 \pm 1.31$ ), IGF 1 deficient patients (mean IGF1 $67.74 \pm 28.96 \mathrm{ng} / \mathrm{ml}$, IGF1 z score $-2.64 \pm 0.51$ ) presented, at diagnosis, higher thyroglobulin (medi- 

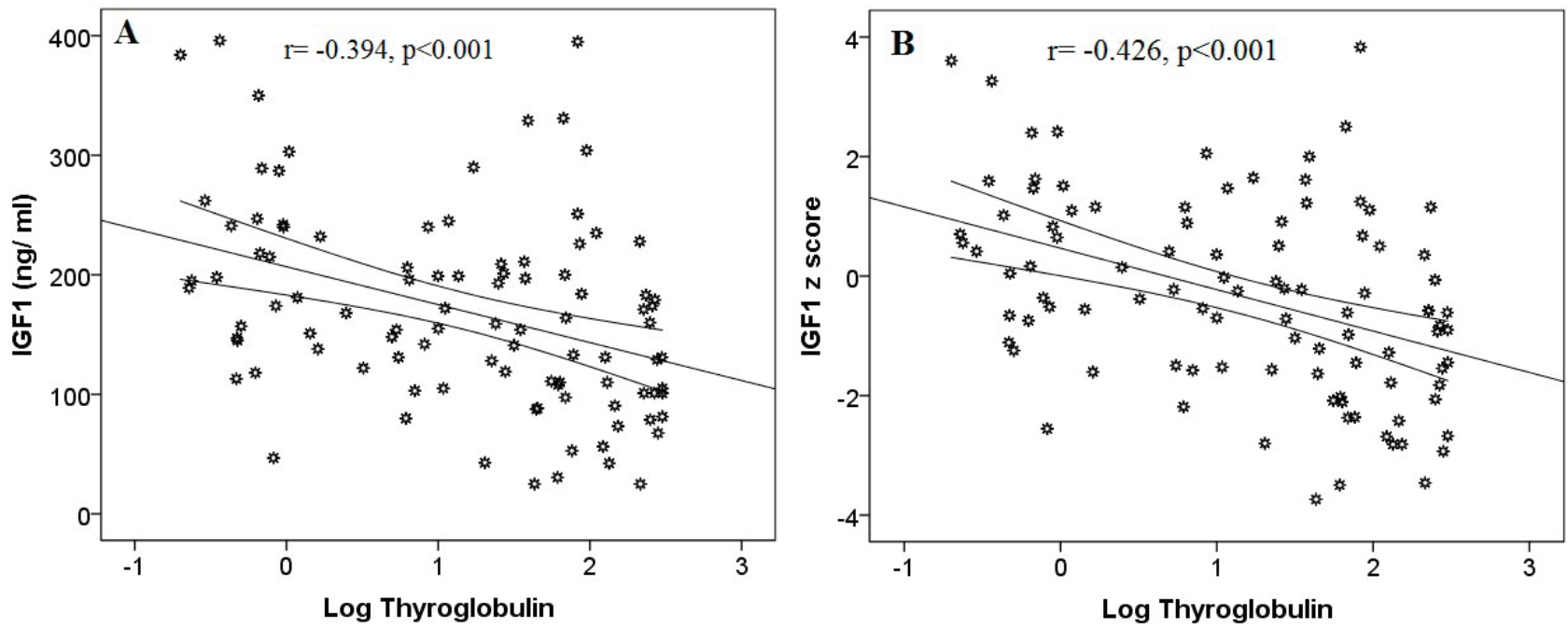

Figure 1. Correlation between IGF1 (A) and IGF1 z score (B) and log-transformed serum thyroglobulin levels.

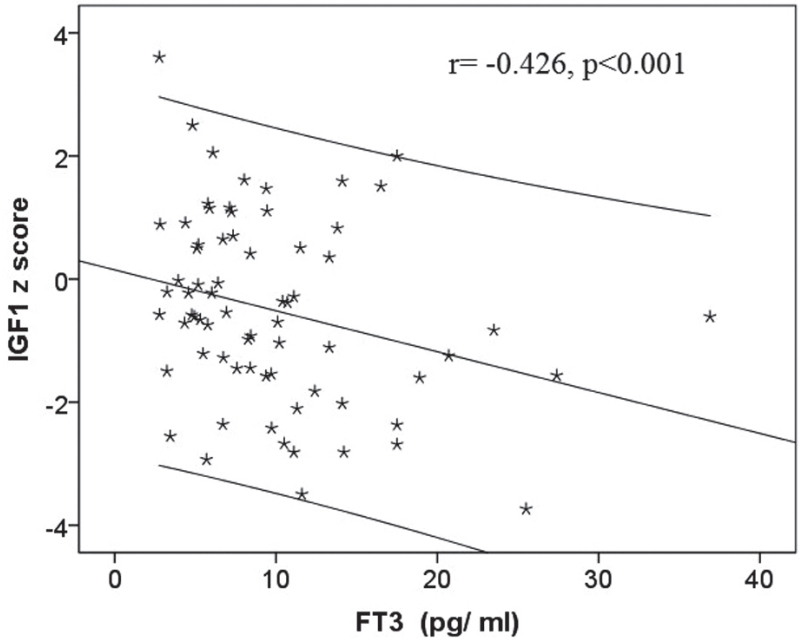

Figure 2. Correlation between IGF1 z score and FT3 at diagnosis.

an=72.55, $\mathrm{IQR}=116.02$ vs median $=11.40, \mathrm{IQR}=80.74$ $\mathrm{ng} / \mathrm{ml}, \mathrm{p}=0.002$ ) (Figure 3A), FT3 (median=11.30, $\mathrm{IQR}=7.64 \mathrm{vs}$ median=7.33, IQR=5.72 pg/ml, $\mathrm{p}=0.027$ ) (Figure 4) and lower ATA levels (median $=20, \mathrm{IQR}=0$ vs median $=34.05, \mathrm{IQR}=161 \mathrm{iu} / \mathrm{ml}, \mathrm{p}<0.001$ ) (Figure 3B) (Table 1).

Univariate binary logistic regression analysis identified log thyroglobulin (OR: 2.97, 95\% CI: 1.403-6.299, $\mathrm{p}=0.004)$ and $\log$ ATA (OR: 0.114, 95\% CI: 0.016$0.802, \mathrm{p}=0.029)$, but not FT3 ( $\mathrm{p}=0.14)$ as idependent predictors of IGF1 deficiency (Table 3). Thyroglobulin was significantly associated with the presence of
Table 2. Univariate linear regression analysis of FT3, thyroglobulin and anti-thyroglobulin antibodies on IGF1 z score.

\begin{tabular}{lcccc}
\hline \multirow{2}{*}{ Parameter } & Coefficient & \multicolumn{2}{c}{$95 \%$ CI } & p \\
\cline { 3 - 4 } & & Lower & Upper & \\
\hline FT3 $(\mathrm{pg} / \mathrm{ml})$ & -0.023 & -0.045 & -0.001 & 0.044 \\
Log thyroglobulin & -0.224 & -0.357 & -0.091 & $<0.001$ \\
(ng/ml) & & & & \\
Log ATA (iu/ml) & 0.241 & 0.028 & 0.454 & 0.027 \\
\hline
\end{tabular}

IGF1: Insulin-like growth factor 1; FT3: free triiodothyronine; Log thyroglobulin: logarithmic transformed thyroglobulin; Log ATA: logarithmic transformed anti-thyroglobulin antibodies.
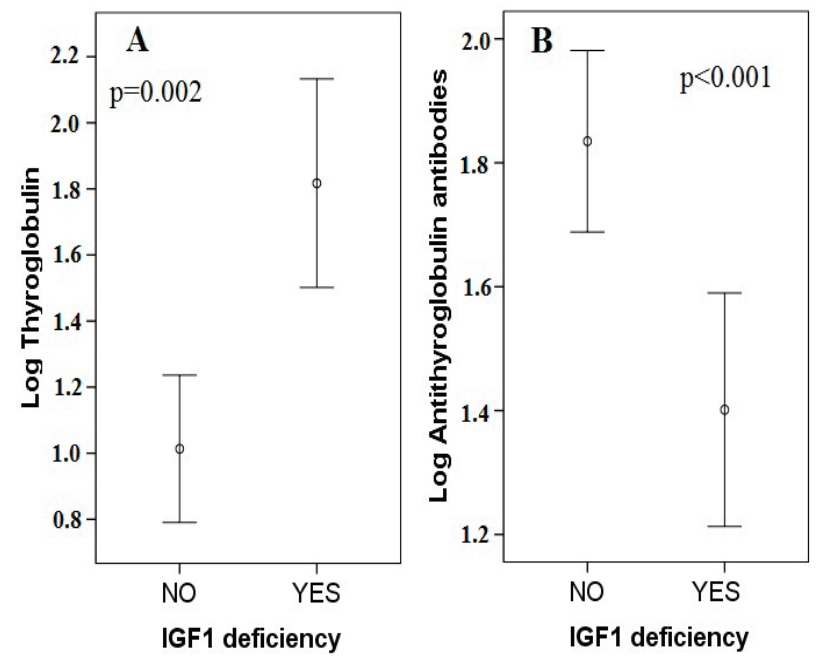

Figure 3. Mean log transformed thyroglobulin (A) and antithyroglobulin antibody (B) values, at diagnosis, according to IGF1 status. 
IGF1 deficiency (AUROC $=0.732,95 \%$ CI: 0.620 $0.844, \mathrm{p}=0.002$; cut-off for thyroglobulin $=50.40 \mathrm{ng} /$ $\mathrm{ml}, \mathrm{Se}=77.8 \%, \mathrm{Sp}=70 \%$ ) (Figure 5).

Table 3. Univariate binary logistic regression analysis of the factors associated with IGF1 deficiency.

\begin{tabular}{lcccc}
\hline Parameter & Odds & \multicolumn{2}{c}{$\mathbf{9 5 \%}$ CI } & \multirow{2}{*}{ p } \\
\cline { 3 - 4 } & Ratio & Lower & Upper & \\
\hline Log ATA $(\mathrm{iu} / \mathrm{ml})$ & 0.114 & 0.016 & 0.802 & 0.029 \\
Log Thyroglobulin $(\mathrm{ng} / \mathrm{ml})$ & 2.97 & 1.403 & 6.299 & 0.004 \\
\hline
\end{tabular}

IGF1: Insulin-like growth factor 1; Log ATA: logarithmic transformed anti-thyroglobulin antibodies; Log thyroglobulin: logarithmic transformed thyroglobulin.

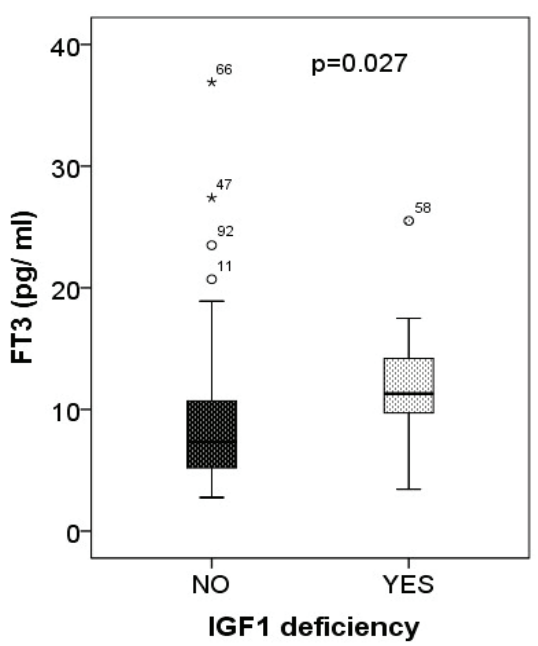

Figure 4. Serum FT3 levels according to IGF1 status, at diagnosis.

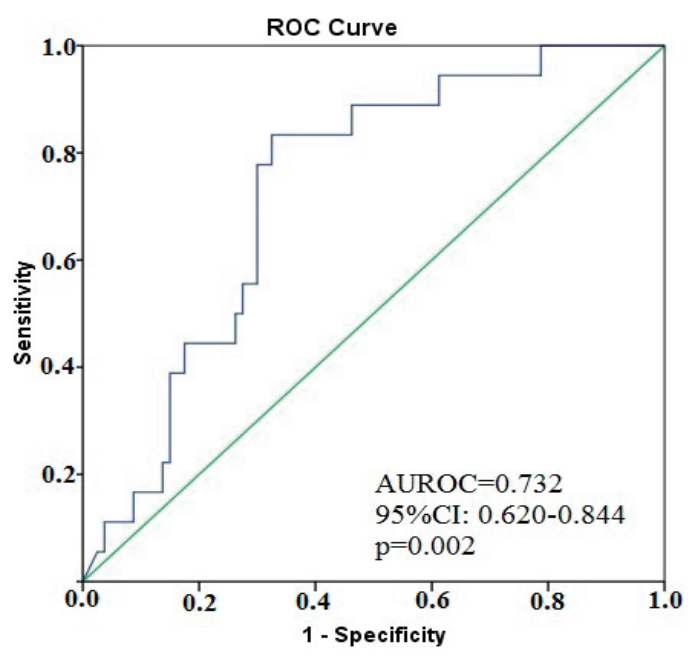

Figure 5. Predictive value of serum thyroglobulin levels on IGF1 deficiency.
IGF1 status was not significantly influenced by gender ( $\mathrm{p}=0.084)$, current smoking $(\mathrm{p}=0.558)$, goiter size $(\mathrm{p}=0.533)$, presence of ophthalmopathy $(\mathrm{p}=0.334)$, TRAb $(\mathrm{p}=0.239)$ or TPOAb $(\mathrm{p}=0.367)$ status. ATA negative patients had a higher prevalence of IGF1 deficiency $\left(28.3 \%\right.$ vs $2.6 \%, \chi^{2}=10.25, \mathrm{p}<0.001$; OR for IGF1 deficiency $10.76,95 \%$ CI: $1.49-77.62$ ) compared to ATA positive patients.

\section{DISCUSSIONS}

In the present study, we investigated serum IGF1 levels in a group of hyperthyroid patients with newly diagnosed GD, without prior antithyroid drug treatment. In order to remove the effect of age on serum IGF1 levels we also analyzed IGF1 z scores. Our data showed that in newly diagnosed hyperthyroid GD patients, IGF1 z score is negatively correlated with the severity of FT3 hyperthyroidism and serum thyroglobulin levels and is positively correlated with ATA levels. Thyroglobulin level at diagnosis was significantly associated with the presence of IGF1 deficiency.

The relationship between the thyroid and the $\mathrm{GH} /$ IGF1 axis is bidirectional. In patients with autoimmune thyroid diseases, thyroid hormones modulate the synthesis and/or the secretion of IGF1 and IGFBP3, and this function is apparently not mediated by GH. ${ }^{20}$ On the other hand, IGF1 and IGF1R play an important role in autoimmunity, the relationship between immune system and growth factors having recently been characterized.

Previous studies reported discrepant results regarding circulating IGF1 levels: lower, ${ }^{8,9}$ unmodified $^{10,11}$ or even higher values ${ }^{12-14}$ in hyperthyroid compared to euthyroid patients. These discrepant results may be due to different laboratory tests used, changes in the number of IGF1R,,$^{21,22}$ an interaction between the anabolic effect of IGF-related peptides and the catabolic thyrotoxic condition ${ }^{16}$ or changes associated with nutritional signals and/or energy balance. ${ }^{23}$

To the best of our knowledge, there are only six studies that evaluated the plasma IGF-related peptides profile in newly diagnosed hyperthyroid GD patients. ${ }^{11,14,20,24-26}$ The previous studies were conducted on a small number of patients, mostly of different ages and genders. The relationship between IGF-related 
peptides and antithyroid antibodies status and titer has been analyzed in only two studies. ${ }^{20,26}$

In our population of 98 GD patients, serum IGF 1 levels and IGF1 z scores were higher in men compared to women. Previous studies, not performed in hyperthyroid populations, have reported similar, ${ }^{27}$ higher ${ }^{28}$ or even lower ${ }^{29}$ IGF1 levels in men.

Current smoking and goiter size did not influence serum IGF1 levels and IGF1 z scores in our population. In an earlier study conducted on 130 healthy adults, smoking, a known risk factor for GD and GO, was independently and positively associated with serum IGF1 levels. ${ }^{30}$ However, a recent study found no correlation between tobacco use and serum IGF1 levels, concluding that smoking does not appear to be a major confounder of the reported clinical associations between IGF1 and specific disease entities. ${ }^{31}$

Our 24 hyperthyroid patients with GD and active GO did not present different serum IGF1 levels or IGF1 z scores when compared to hyperthyroid GD patients without GO. Only one study has investigated serum IGF1, IGF2, IGFBP1, IGFBP2 and IGFBP3 in euthyroid GD patients with active GO and reported that IGF1 related peptides are not higher compared to those in healthy adults..$^{32}$ Thus, previously reported retrobulbar elevated IGF1 levels seem to be independent of serum IGF1 concentration, probably being an expression of an auto/paracrine activity.

Our study showed no association between TRAb or TPOAb status and titer and serum IGF1 levels or IGF1 z scores. Consistent with our data, Zimmermann-Belsing et al, in a study of 24 hyperthyroid women with GD, did not identify TPOAb and TRAb as significant predictors for total IGF1. ${ }^{26}$

In our newly diagnosed GD hyperthyroid patients, higher FT3 and thyroglobulin, and respectively lower ATA serum levels were associated with lower IGF1 $\mathrm{z}$ scores (Figures 1,2). Previous data regarding the relationship between IGF system and thyroid hormones in GD patients are discrepant. Thyroid hormones were either positively correlated with IGFBP3 and/ or IGF $1^{11,14,20}$ or negatively correlated with IGFBP3 and ALS. ${ }^{26}$

Eighteen (18) (18.4\%) of our GD patients had, at diagnosis, IGF1 deficiency, defined as IGF1 z score $\leq-2$ DS. Interestingly, these patients had higher thyroglobulin and FT3, and respectively lower ATA levels (Figure 3, 4). Univariate binary logistic regression analysis identified thyroglobulin and ATA, but not FT3, as idependent predictors for IGF1 deficiency. We identified a cut-off level for serum thyroglobulin of $50.40 \mathrm{ng} / \mathrm{ml}$ as a strong predictor for IGF1 deficiency, with $\mathrm{Se}=77.8 \%$ and $\mathrm{Sp}=70 \%$. Patients with thyroid disorders may present with, even several years after reaching euthyroidism, other complications such as: memory impairment, ${ }^{33}$ depression, ${ }^{34}$ fatigue or body composition changes, ${ }^{35}$ signs and symptoms that are also described in patients with GH deficiency. It is known that in thyrotoxicosis protein catabolism predominates, leading to a slight decrease in serum total protein concentration. ${ }^{36}$ Furthermore, it was demonstrated that serum IGF1 levels are low in severe catabolic states such as acute postoperative stress, burns, cystic fibrosis or $\mathrm{HIV}^{37}$ and that the recovery from the catabolic states is associated with increased levels of IGF $1 .{ }^{38}$ Thus, thyrotoxicosis, a catabolic state, could be associated with a decrease of IGF1 levels and clinical manifestations similar to partial GH deficiency, potentially corroborating our results. These findings are however in contradiction with the data from other studies reporting high IGF1 levels in hyperthyroidism, that decreased after ATDs treatment. ${ }^{14,26}$ Zimmermann-Belsing et al suggest that the complex IGF system seems intact in thyrotoxic patients, but changes in body composition and the regulation of leptin and insulin secretion during treatment of autoimmune thyroid disease influence IGF related peptides leaving the patient in a state somewhat similar to partial GH deficiency. ${ }^{26}$

The proinflammatory cytokines TNF alfa and IL1 beta often act as negative regulatory signals that temper the action of hormones and growth factors and may induce a state of IGF1 resistance ${ }^{39}$ However, we found no correlation between inflamatory markers HS-PCR, TNF alfa and IGF1 or IGF1 z scores in our GD patients.

Our study has some strengths as well as several limitations. Although we studied a relatively large population of GD patients, we cannot exclude that we could have missed associations of smaller magnitude due to low statistical power. Another limitation is that we did not compare the GD patients IGF1/IGF1 z-score 
values with a control group of healthy individuals, without pathologies known to influence the GH/IGF1 axis. Also, we could not extensively study the IGF protein system (IGF1, free IGF1, IGF2, IGFBP3, ALS) and we did not follow the dynamics of IGF1 after ATD treatment. Nevertheless, we believe that our results contribute some important novel information and deserve further validation in large-scale prospective studies.

In conclusion, the present study has shown for the first time the presence of IGF1 deficiency in nearly one fifth of newly diagnosed GD patients. The IGF1 deficient GD patients' phenotype was characterized by lower ATA titers, higher thyroglobulin levels and more severe FT3 hyperthyroidism at diagnosis.

\section{ACKNOWLEDGEMENT}

This paper was partly supported by the Sectorial Operational Programme Human Resources Development (SOPHRD), financed by the European Social Fund and the Romanian Government under the contract number POSDRU 141531.

\section{CONFLICTS OF INTEREST}

The authors have no multiplicity of interest to disclose.

\section{Note}

Part of this report was accepted as a poster at the 17th European Congress of Endocrinology, Dublin, Republic of Ireland, 2015.

\section{REFERENCES}

1. Rapoport B, McLachlan SM, 2007 The thyroptin receptor in Graves' disease. Thyroid 17: 911-922.

2. Eckstein AK, Plicht M, Lax H, et al, 2006 Thyrotropin receptor autoantibodies are independent risk factors for Graves' ophthalmopathy and help to predict severity and outcome of the disease. J Clin Endocrinol Metab 91: 3464-3470.

3. Gerding MN, Van der Meer JWC, Broenink M, et al, 2000 Association of thyrotrophin receptor antibodies with the clinical features of Graves' ophthalmopathy. Clin Endocrinol 52: 267-271.

4. Bartalena L, Fatourechi V, 2014 Extrathyroidal manifestations of Graves' disease: a 2014 update. J Endocrinol Invest 37: 691-700.
5. Tramontano D, Cushing GW, Moses AC, Ingbar SH, 1986 Insulin-like growth factor-I stimulates the growth of rat thyroid cells in culture and synergizes the stimulation of DNA synthesis induced by TSH and Graves'-IgG. Endocrinology 119: 940-942.

6. Wiersinga WM, 2011 Autoimmunity in Graves' Ophthalmopathy: The Result of an Unfortunate Marriage Between TSH Receptors and IGF-1 Receptors. J Clin Endocrinol Metab 96: 2386-2394.

7. Tsui S, Naik V, Hoa N, et al, 2008 Evidence for an association between thyroid-stimulating hormone and insulin-like growth factor 1 receptors: a tale of two antigens implicated in Graves' disease. J Immunol 181: 4397-405.

8. Frystyk J, Grønbaek H, Skjaerbaek C, Flyvbjerg A, 1995 Effect of hyperthyroidism on circulating levels of free and total IGF-I and IGFBPs in rats. Am J Physiol 269: 840-845.

9. Ramos-Dias JC, Yateman M, Camacho-Hübner C, Grossman A, Lengyel AM, 1995 Low circulating IGF-I levels in hyperthyroidism are associated with decreased $\mathrm{GH}$ response to GH-releasing hormone. J. Clinical Endocrinology 43: 583-589.

10. Iglesias P, Bayon C, Mendez J, Gancedo PG, Grande C, Diez JJ, 2001 Serum insulin-like growth factor type 1 , insulin-like growth factor-binding protein-1, and insulin-like growth factor-binding protein-3 concentrations in patients with thyroid dysfunction. Thyroid 11: 1043-1048.

11. Co Ng LL, Lang CH, Bereket A, Purandare A, Smaldone A, Wilson TA, 2000 Effect of hyperthyroidism on insulin-like growth factor-I (IGF-I) and IGF-binding proteins in adolescent children. J. Pediatr Endocrinol Metab 13: 1073-1080.

12. Valcavi R, Dieguer C, Zini M, Muruais C, Casanueva F, Portioli I, 1993 Influence of hyperthyroidism on growth hormone secretion, Influence of hyperthyroidism on growth hormone secretion. J Clinical Endocrinology 38: 515-522.

13. Miell JP, Taylor AM, Zini M, Maheshwari HG, Ross RJ, Valcavi R, 1993 Effects of hypothyroidism and hyperthyroidism on insulin-like growth factors (IGFs) and growth hormone- and IGF-binding proteins. J Clin Endocrinol Metab 76: 950-955.

14. Lakatos P, Foldes J, Nagy Z, et al, 2000 Serum insulinlike growth factor-I, insulin-like growth factor binding proteins, and bone mineral content in hyperthyroidism. Thyroid 10: 417-423.

15. Krassas GE, Pontikides N, Kaltsas T, et al, 2003 Free and total insulin-like growth factor (IGF)-I, -II, and IGF binding protein-1, -2 , and -3 serum levels in patients with active thyroid eye disease. J Clin Endocrinol Metab 88: 132-135.

16. Werner SC, 1977 Modification of the classification of the eye changes of Graves' disease: recommendations of the ad hoc committee of the American Thyroid Asso- 
ciation. J Clin Endocrinol Metab 44: 203-209.

17. Mourits MP, Prummel MF, Wiersinga WM, Koornneef L, 1977 Clinical activity score as a guide in the management of patients with Graves' ophthalmopathy. Clin Endocrinol (Oxford) 47: 9-14.

18. Elmlinger MW, Kuhnel W, Weber NM, Ranke MB, 2004 Reference ranges for two automated chemiluminescent assays for serum insulin-like growth factor I (IGF-I) and IGF-binding protein 3 (IGFBP-3). Clin Chem Lab Med 43: 654-664.

19. Glynn N, Agha A, 2012 Diagnosing growth hormone deficiency in adults. Int J Endocrinol 2012: 972617.

20. Inukai T, Takanashi K, Takebayashi K, Fujiwara Y, Tayama K, Takemura Y, 1999 Thyroid hormone modulates insulin-like growth factor-I(IGF-I) and IGF-binding protein-3, without mediation by growth hormone, in patients with autoimmune thyroid diseases. Horm Metab Res 31: 576-579.

21. Cissewski K, Wolf M, Moses AC, 1992 Characterization of insulin-like growth factor receptors in human thyroid tissue, Receptor 2: 145-153.

22. Hsiao PJ, Tsai JH, 1994 Increased insulin-like growth factor-1 receptors in thyroid tissues of Graves' disease. J Formos Med Assoc 93: 925-932.

23. Morovat A, Dauncey MJ, 1998 Effects of thyroid status on insulin-like growth factor-I, growth hormone and insulin are modified by food intake. Eur J Endocrinol 138: 95-103.

24. Tada H, Watanabe Y, Futakuchi Y, Amino N, 1994 Change in serum concentration of insulin-like growth factor II (IGF-II) in patients with thyroid disease. Endocr J 41: 541-545.

25. Wan Nazaimoon WM, Khalid BA, 1998 Insulin-like growth factor binding protein-3 (IGFBP-3) but not insulin-like growth factor-I (IGF-I) remains elevated in euthyroid TSH-suppressed Graves disease. Horm Metab Res 30: 213-216.

26. Zimmermann-Belsing T, Juul A, Juul Holst J, FeldtRasmussen U, 2004 The insulin-like growth axis in patients with autoimmune thyrotoxicosis: effect of antithyroid drug treatment. Growth Horm IGF Res 14: 235-244.

27. Rosario PW, 2010 Normal values of serum IGF-1 in adults: results from a Brazilian population. Arq Bras Endocrinol Metabol 54: 477-481.
28. Colao A, Di Somma C, Cascella T, et al, 2008 Relationships between serum IGF1 levels, blood pressure, and glucose tolerance: an observational, exploratory study in 404 subjects. Eur J Endocrinol 159: 389-397.

29. Vestergaard PF, Hansen M, Frystyk J, et al, 2013 Serum levels of bioactive IGF1 and physiological markers of ageing in healthy adults. Eur J Endocrinol 170: 229-236.

30. Kaklamani VG, Linos A, Kaklamani E, Markaki I, Mantzoros C, 1999 Age, sex, and smoking are predictors of circulating insulin-like growth factor 1 and insulin-like growth factor-binding protein 3. J Clin Oncol 17: 813-817.

31. Palmer RM, Wilson RF, Coward PY, Scott DA, 2002 Analysis of circulating insulin-like growth factor-1 (IGF-1) and IGF binding protein-3 (IGFBP-3) in tobacco smokers and non-smokers. Tob Induc Dis 1: 157-170.

32. Krassas GE, Pontikides N, Kaltsas T, et al, 2003 Free and total insulin-like growth factor (IGF)-I, -II, and IGF binding protein-1, -2 , and -3 serum levels in patients with active thyroid eye disease. J Clin Endocrinol Metab 88: 132-135.

33. Perrild H, Hansen JM, Arnung K, Olsen PZ, Danielsen U, 1986 Intellectual impairment after hyperthyroidism. Acta Endocrinol (Copenh) 112: 185-191.

34. Kirkegaard C, Faber J, 1998 The role of thyroid hormones in depression. Eur J Endocrinol 138: 1-9.

35. Lonn L, Stenlof K, Ottosson M, Lindroos AK, Nystrom E, Sjostrom L, 1998 Body weight and body composition changes after treatment of hyperthyroidism. J Clin Endocrinol Metab 83: 4269-4273.

36. Muller MJ, Seitz HJ, 1984 Thyroid hormone action on intermediary metabolism. Part III. Protein metabolism in hyper- and hypothyroidism. Klin Wochenschr 62: 97-102.

37. Puche JE, Castilla-Cortázar I, 2012 Human conditions of insulin-like growth factor-I (IGF-I) deficiency. J Transl Med 10: 224.

38. Clemmons DR, 2006 Clinical utility of measurements of insulin-like growth factor 1. Nat Clin Pract Endocrinol Metab 2: 436-446.

39. O'Connor JC, McCusker RH, Strle K, Johnson RW, Dantzer R, Kelley KW, 2008 Regulation of IGF-I function by proinflammatory cytokines: at the interface of immunology and endocrinology. Cell Immunol 252: 91-110. 